\title{
The Impact of COVID-I9 Pandemic on the Relationship between India's Volatility Index and Nifty 50 Returns
}

\author{
Jyothi Chittineni $P h D$ \\ Assistant Professor (Finance and Accounting) \\ IBS - Hyderabad, The ICFAI Foundation for Higher Education \\ (Declared as Deemed-to-be University U/s 3 of the UGC Act 1956) \\ Dontanapally Campus, Shanker Pally Road, Hyderabad, India \\ E-mail: Jyothi.kurra@gmail.com
}

Received: July I3, 2020

Accepted: July 29, 2020

Online Published: August 25, 2020

doi: I0.4628I/ijfb.v4i2.73I

URL: https://doi.org/I0.4628I/ijfb.v4i2.73I

\begin{abstract}
The paper intends to re-examine the relationship between India's Implied Volatility Index (IVIX) and Nifty 50 Returns during this COVID-I9 pandemic. The study results are important for two reasons, one is to understand whether Indian VIX is fulfilling the purpose of measuring the near future volatility of Nifty 50 during this pandemic, and secondly, it reports the impact of COVID-I9 on the investors' perceptions about the returns and its volatility. The study results documented that the Nifty return and IVIX are moving independently during the COVID-I9 pandemic and there is no association between market size and the market move. The one period lagged Nifty returns have a significant influence on the future market volatility. The combined impact of negative and positive Nifty returns on IVIX is not significant during the COVID-19 period. This implies that the Indian investors are not much worried about the fluctuation in the market price or size of the market during the COVID-I9 pandemic period. The investors might be taking the market decline as an opportunity to invest and market rise as an opportunity to sell the stocks. Indian investors are much focused on the fundamentals than the market movements during this pandemic. The study results are important for the fund managers, policymakers, and analysts to understand the dynamics of emerging market volatility and the trading behavior of Indian investors.
\end{abstract}

Keywords: India VIX, Inter-Temporal Relation, Asymmetric Relation, Nifty Returns, COVID-I9.

\section{Introduction}

Unforeseen events like global recessions, terrorist attacks, dot-com bubble and pandemics will cause panic among the investors and it leads to large selling pressure, and increases market volatility. The literature documented on the panic selling and due to black swan events like SARS Outbreak and terrorist attacks (Chen \& Siems, 2004; Chen, Jang, \& Kim, 2007; Papakyriakou, Sakkas, \& Taoushianis, 2019). Since this COVID-I9 outbreak, many articles have been published on the impact of COVID-I9 on people's health, businesses, and economies. Certainly, this unknown Coronavirus (COVID-I9) is a game-changer for many industries, people, and Nations. It has changed individuals' perceptions, thinking, and habits. This unpredicted shift in the people's mindset has impacted the businesses heavily. Hence, the study results are important for us to understand the impact of individuals' perceptions on the market fluctuations and its future volatility during this COVID-I9 pandemic period. The scholars and media reported how this pandemic affected the stock markets ${ }^{i}$. An inappropriate event generated an opportunity to measure the impact of the pandemic on the investors' perceptions about the stock market returns and its volatility dynamics.

\section{I.I India VIX}

The Indian VIX measures the expected future volatility of the Nifty index in the next 30 days period. While making investment decisions, investors look at this to understand the market sentiments. It is described as a fear gauge as it reflects the market participants' fear and greed. The correlation between its underlying series Nifty 50 and IVIX is negative. The value of IVIX is at its high when the Nifty closing is at its low and vice-versa. Figure I is a graphical representation of the Nifty closing price and IVIX.

Based on the research work published by Whaley (I993) CBOE introduced VIX in the year I993, soon it has become the benchmark to understand the volatility of the US stock market. Currently, there are around 68 implied volatility indices across all asset classes like equity, commodity, bond, and currency pairs. India introduced IVIX in March 2009. The IVIX is calculated based on the Nifty options order book. The purpose of IVIX is to depict the volatility of in the near future. 


\section{I.2 Theoretical Background}

The negative relationship between future market volatility and its underlying market returns is the interest of academic researchers, investors, and analysts. The literature on volatility documented a negative association between future market volatility and market returns (Merton, 1973a, 1973b; Campbell \& Hentschel, 1992). The stock returns become more volatile to the negative news than the positive news; this is termed 'the leverage effect' in Finance. Two types of theories are documented in the finance literature, relating to a negative relationship between market returns and future market volatility. Both hypotheses believe that there is a strong negative association exists between the current price and its future market volatility. The leverage hypothesis (Black, 1976) states that the equity value of the firm becomes a small percentage of total firm value, if the value of the firm decreases. This lesser portion of equity shareholders must bear the entire firms' risk, subsequently the volatility of equity increases. This effect is termed as the leverage effect. The other theory, volatility feedback effect states that the positive shock to volatility increases the internal rate of return and necessitates the current market price decline to accommodate these future high returns (French, Schwert, \& Stambaugh, 1987; Campbell and Hentschel, 1992). In other words, as the future expected returns decrease when volatility decreases, then the current market returns will fall to accommodate these future expectations. Both hypotheses confirm that there is a strong negative association between asset yields and market fluctuations.

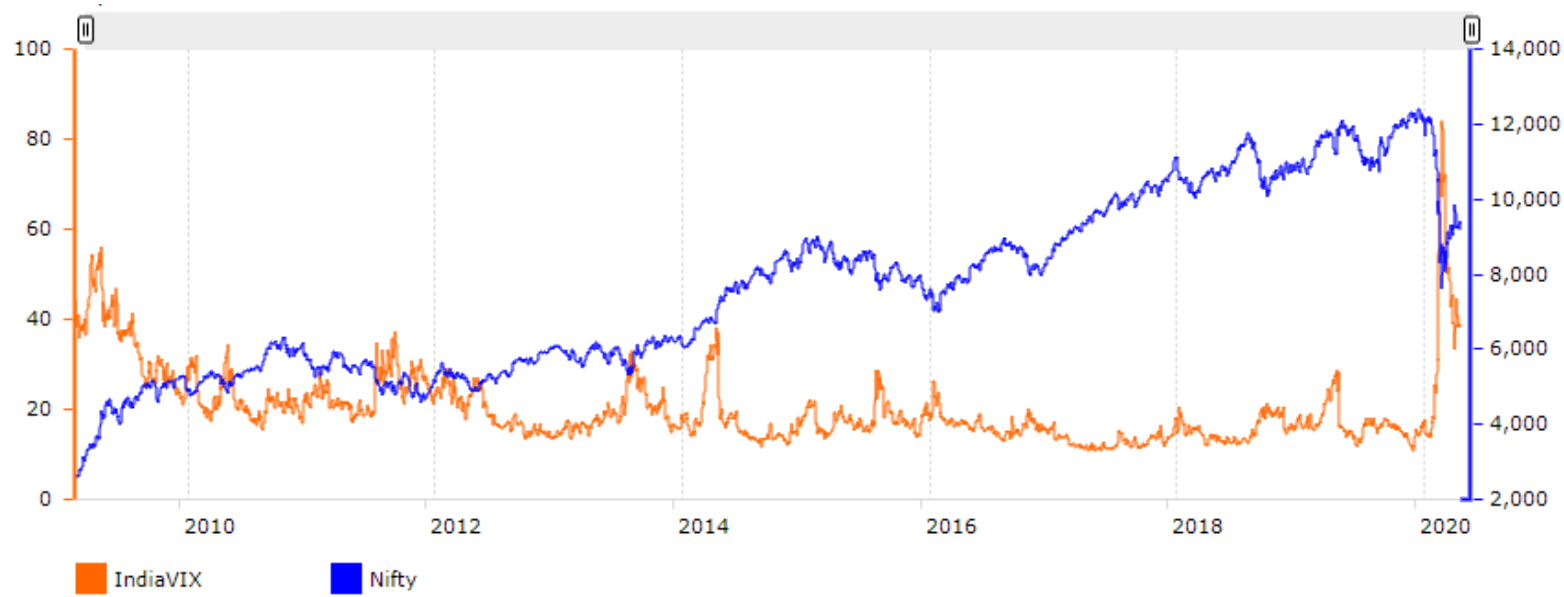

FigureI. The relationship between Nifty returns series and India VIX

Source: http://www.traderscockpit.com/?pageView=india-volatility-index-chart-vs-nifty-chart

\section{Review of Literature}

The first empirical study on the implied volatility index is conducted by Fleming, Ostdiek, and Whaley (I995), they have used VIX as a measure of market volatility. Bekaert and $\mathrm{Wu}(2000)$ tried to identify the sources for the asymmetry between stock returns and VIX. The study 'understanding the VIX' by Whaley (2009) reported that VIX and the market price are moving in an opposite trend. Skiadopoulos (2004); Hibbert, Daigler, and Dupoyet (2008) and Frijns, Tallau, and TouraniRad (2010) tested the association between implied volatility index and its underlying stock index returns, these studies supported the findings of the earlier studies and conformed a significant negative association between VIX and market returns. the literature documented that the negative returns have a stronger effect on VIX than the positive returns. In other words, investors are more sensitive to negative shocks than positive news. The literature confirms thatmarket volatility is not responding identically to positive and negatives shocks.

In the Indian context, the paper by Shaikh and Padhi (2015) examined the inter-temporal relationship between market returns and Indian VIX, the findings supported the earlier results and confirmed the negative association between Indian VIX and its underlying stock returns. Chandra and Thenmozhi (2015) revealed that the India VIX and its underlying index are moving independently during the upward movements and the association between India VIX and Nifty returns series is not significant when the markets take a sharp downward turn. Dhanaiah, Reddy and Prasad (2012) used the OLS model and the findings suggested that the relationship between stock returns and IVIX change is asymmetrical.

A study conducted on developed economies by Kudryavtsev (2017) documented both negative and positive large price changes are complemented by the contemporaneous opposite-sign in the volatility index. The study also documented a significant reversal trend and it is significant in longer post-event windows. Siddiqui and Roy (2019) explored the contemporaneous negative relationship between stock returns, India VIX, and trading volumes. The results suggested that the leverage effect is significant for a lagged period. Contradicting the existing literature, (Chakrabarti \& Kumar, 2020; Fousekis, 2020) reported an interesting finding that the dynamic association between these series is statistically inadequate to support the traditional hypotheses namely leverage effect and volatility feedback effect. Fousekis (2020) documented a reverse S-shape association between stock returns and VIX in the US, Australia, and the EU markets. 
An examination of the contemporaneous correlation between stock returns and IVIX is relatively new. The existing review of the literature highlights limited studies on Indian VIX and Nifty returns. Most of the literature is focused on developed economies and very few studies are conducted on emerging economies like India. The studies conducted on the Indian context reported mixed results. Thus, this study is critical for two reasons, one is to know whether IVIX is fulfilling the purpose of measuring the near future expected volatility of Nifty returns during this COVID-I9 period. Second, the study reports the influence of COVID-I9 on the relationship between the NIFTY returns and India VIX. This paper complements the literature by reporting the impact of COVID-I9 on the relationship between market returns and Indian VIX.

\section{Data and Methodology \\ 3.I Data}

The daily closing India VIX values and daily closing values of the Nifty 50 index are collected from the NSE website. India introduced IVIX on $2^{\text {nd }}$ March 2009 and the data for IVIX is available from that date, hence the sample data is collected from $2^{\text {nd }}$ March 2009 to $30^{\text {th }}$ June 2020.

The analysis is presented before the COVID-I9 period (hereinafter PRE-COVID-I9) and for the COVID-I9 period (hereinafter COVID-I9). Hence sample data for PRE-COVID-I9 is from 2nd March 2009 to 3Ist October 2019 and the COVID-I9 period is from Ist November 2019 to 30th June 2020. The total observations that are collected for the study are 2950. Table I presents summary statistics for IVIX change and Nifty returns

Table I. Summary statistics of IVIX and Nifty returns

\begin{tabular}{lllll}
\hline & \multicolumn{2}{l}{ COVID-I9 PERIOD } & \multicolumn{2}{l}{ PRE-COVID-I9 } \\
\hline Mean & $\Delta$ VIX & Nifty_Returns & $\Delta$ VIX & Nifty_Returns \\
\hline Median & -0.000884 & 0.006060 & -0.000642 & 0.000564 \\
\hline Maximum & 0.000445 & -0.006276 & -0.003308 & 0.000624 \\
\hline Minimum & 0.084003 & 0.307909 & 0.496881 & 0.163343 \\
\hline Std. Dev. & -0.139038 & -0.105019 & -0.414379 & -0.139038 \\
\hline Skewness & 0.023476 & 0.071204 & 0.051754 & 0.012049 \\
\hline Kurtosis & -1.478836 & 1.981081 & 0.451944 & 0.135389 \\
\hline Jarque-Bera & 12.27599 & 8.298575 & 10.09984 & 24.48061 \\
\hline Probability & 635.8955 & 293.6481 & 6238.748 & 56205.60 \\
\hline
\end{tabular}

The change in IVIX is calculated on the percentage change, $\frac{\left(I V I X_{t}-I V I X_{t-1}\right)}{I V I X_{t}}$.

The Nifty returns are calculated based on continuous compounding, $\ln \left(\frac{\text { Nifty }_{t-1}}{{\text { nif } t y_{t}}_{t}}\right)$.

\subsection{Methodology}

3.2.I The Asymmetric relationship between Nifty returns and $\Delta$ IVIX

Fleming et al. (1995) examined the contemporaneous relationship between VIX change and its underlying series. He proposed a multivariate model for his study. This model is a linear regression model, he regressed two leads, two lags and absolute values of VIX with its underlying index returns. Earlier studies (Frijns et al. 20I0, Shaikh \& Padhi, 20I5) adopted this model to examine the asymmetric relationship between market returns and the future market volatility. The model representation is as follows:

$$
\begin{aligned}
& \Delta I V I X=\alpha+\alpha_{1} \text { Nifty return }_{t-2}+\alpha_{2} \text { Nifty returns }_{t-1}+\alpha_{3} \text { Nifty retruns }_{t}+\alpha_{4} \text { Nifty retruns }_{t+1}+ \\
& \alpha_{5} \text { Nifty return }_{t+2}+\alpha_{6} \mid \text { Nifty return } s_{t} \mid+\alpha_{7} \Delta I V I X_{t-1}+\mu_{t} \ldots(\mathrm{I})
\end{aligned}
$$

Equation (I) measures the contemporaneous inter-temporal relationship in the lead-lag from between Nifty returns and IVIX change. If the model coefficients are significant and negative, then it indicates that there is an increase in the $\Delta$ IVIX for a decrease in the Nifty returns and vice-versa. To elaborate further on this, a negative and significant slope of Nifty returns $s_{t-2}$ signifies a negative association between stock returns at ( $\left.\mathrm{t}-2\right)$ with $\Delta$ IVIX at the time ' $t$ '. A positive slope coefficient of Nifty returns $s_{t}$ indicates that the Nifty returns and IVIX are independent. The difference of the slopes between Nifty returns and absolute Nifty returns at the time ' $t$ ' measures the asymmetric relationship between Nifty returns and IVIX.

Equation I is estimated with the "COVID-I9" data set and "PRE-COVID-I9" data set.

\subsubsection{Unit Root Tests Result for Nifty 50 Returns and IVIX}

Both the indices are examined for stationarity using ADF and PP tests. The unit root tests are conducted for trend and intercept. The estimated values are reported in Table-2. The optimum lag length is tested by using Schwartz Information 
Criterion. Unit root tests reject the null hypothesis in each series at I\% level of significance, and both the test results are confirming the stationarity of Nifty returns and $\Delta$ IVIX series.

Table 2. Unit test results for $\Delta$ IVIX and Nifty 50 returns series

\begin{tabular}{|c|c|c|c|c|}
\hline $\begin{array}{l}\text { COVID-I9 } \\
\text { before } \\
\text { sample }\end{array}$ & Intercept & $\begin{array}{l}\text { Trend and } \\
\text { Intercept }\end{array}$ & Intercept & Trend and Intercept \\
\hline $\mathrm{ADF}$ & $\begin{array}{l}-5 \mathrm{I} . \mathrm{I} 7285 \\
(0.000)\end{array}$ & $\begin{array}{l}-51.18399 \\
(0.000)\end{array}$ & $\begin{array}{l}-19.86345 \\
(0.000)\end{array}$ & $\begin{array}{l}-20.04343 \\
(0.000)\end{array}$ \\
\hline PP & $\begin{array}{l}-5 \text { I.I I } 296 \\
(0.000)\end{array}$ & $\begin{array}{l}-51.12210 \\
(0.000)\end{array}$ & $\begin{array}{l}-50.34365 \\
(0.000)\end{array}$ & $\begin{array}{l}-50.38029 \\
(0.000)\end{array}$ \\
\hline $\begin{array}{l}\text { COVID-I9 } \\
\text { sample }\end{array}$ & $\Delta \mathrm{IVIX}$ & & Nifty Returns & \\
\hline $\mathrm{ADF}$ & $\begin{array}{l}-0.759168 \\
(0.000)\end{array}$ & $\begin{array}{l}-0.759608 \\
(0.000)\end{array}$ & $\begin{array}{l}-\mathrm{I} . \mathrm{I} 70600 \\
(0.000)\end{array}$ & $\begin{array}{l}-\mathrm{I} . \mathrm{I} 72028 \\
(0.000)\end{array}$ \\
\hline $\mathrm{PP}$ & $\begin{array}{l}-0.759168 \\
(0.000)\end{array}$ & $\begin{array}{l}-0.759608 \\
(0.000)\end{array}$ & $\begin{array}{l}-\mathrm{I} . \mathrm{I} 70600 \\
(0.0000)\end{array}$ & $\begin{array}{l}-\mathrm{I} .172028 \\
(0.000)\end{array}$ \\
\hline
\end{tabular}

Note: Mackinnon's critical values are exceeding their test statistic values at $1 \%, 5 \%$, and $10 \%$ levels. The ' $\mathrm{p}$ ' values are presented within the parenthesis.

\section{Empirical Analysis}

\section{I Relationship between Market Returns and IVIX}

The IVIX is described as fear gauge or fear index. It is used to measure the investor's expectations about future market returns in the near period. Hence, understanding the relationship between Nifty returns and IVIX got attention from analysts and investors. The graphical representation of Nifty closing and India VIX series is presented in FigureI. The visual observation of Figure I shows a clear negative relationship between Nifty closing and IVIX values. The IVIX series moves up for a fall in Nifty closing values and down for an increase in Nifty closing values. The movement of IVIX for a change in Nifty closing values is opposite but not asymmetric. This visual observation is empirically tested for statistical significance by using equation (I). The results for PRE-COVID-I9 and during the COVID-I9 period are tabulated in Table 3.

Table 3. Multivariate Regression Results

\begin{tabular}{|c|c|c|c|c|c|c|}
\hline & COVID peri & & & Pre-COVID & & \\
\hline Slope & Coefficients & $p$-value & $T$ stat & Coefficients & p-value & $T$ stat \\
\hline$\alpha$ & $-2.34 I$ & 0.2263 & & -4.5945 & $0.982 I$ & \\
\hline $\begin{array}{c}\alpha_{1} \\
\text { Niftyreturns } s_{t-2}\end{array}$ & 0.739508 & 0.2375 & & 5.2754 & 0.000 & \\
\hline $\begin{array}{c}\alpha_{2} \\
\text { Niftyreturns } s_{t-1}\end{array}$ & 2.373013 & 0.000 & & 0.01145 & 0.000 & \\
\hline $\begin{array}{c}\alpha_{3} \\
\text { Niftyretruns }\end{array}$ & -0.09017 & 0.1493 & & -0.0047 & 0.0238 & \\
\hline $\begin{array}{c}\alpha_{4} \\
\text { Niftyretruns } s_{t+1}\end{array}$ & -0.05466 & 0.72069 & & -0.0026 & 0.9810 & \\
\hline $\begin{array}{c}\alpha_{5} \\
\text { Niftyreturns } s_{t+2}\end{array}$ & 0.068713 & 0.914594 & & 0.0083 & 0.2590 & \\
\hline $\begin{array}{c}\alpha_{6} \\
\mid \text { Niftyreturns }\end{array}$ & 0.0331 & 0.308645 & & 13.8766 & 0.3894 & \\
\hline $\begin{array}{c}\alpha_{7} \\
\Delta I V I X_{t-1}\end{array}$ & 0.067797 & 0.0003 & & 0.08797 & 0.000 & \\
\hline$\Gamma-=\alpha_{3}-\alpha_{6}$ & -0.12326 & & 0.3798 & 13.8813 & & $2.00 I$ \\
\hline$\Gamma+=\alpha_{3}+\alpha_{6}$ & 0.057065 & & & 13.8719 & & \\
\hline Adj-R squared & 0.2987 & & & 0.4917 & & \\
\hline
\end{tabular}




\subsection{PRE-COVID-19 Analysis}

The PRE-COVID-I9 data set result suggests that there exists a significant negative correlation between Nifty returns and IVIX. The estimated coefficient for the absolute Nifty returns is positive but not statistically significant, which indicates that there is no considerable association between market move and the size of the market. The study results are partially confirming with the earlier studies like (Fleming et al., I995; Shaikh, \& Padhi, 20I5). One period lagged IVIX values and two periods lagged Nifty returns have a significant impact on the IVIX values. Fleming et al. (1995) explained that there should be a significant positive association between VIX and past and present market returns if the VIX measures the expected future market volatility. The study result confirms that the IVIX measures the expected future market volatility of Nifty Market returns, hence investor can use IVIX values to understand the near future market volatility.

To understand the impact of Nifty positive and negative returns on future market volatility, the parameters $\Gamma$-and $\Gamma+$ are estimated by subtracting and adding the coefficients of Nifty returns and its absolute values respectively. The joint effect is tested with Wald F-statistic. The estimated coefficients for $\Gamma(\mathrm{I} 3.8813)$ and $\Gamma$ (I3.87I9) are not statistically significant. The earlier studies suggested that the negative stock returns have a greater influence on future expected market volatility than the positive market returns; the current study results have no significant evidence to support this argument.

\subsection{COVID-19 Period Analysis}

To understand the effect of COVID-I9 pandemic on the association between Nifty returns and IVIX equation number (I) is estimated for the sub-sample data from Ist November 2019 to $30^{\text {th }}$ June 2020 . The estimated Nifty returns coefficient is negative $(-0.090165)$ but it is not statistically significant. The result indicates that there is no significant association between market returns and their future expected volatility which implied during this pandemic period the market returns and expected future volatility are independently moving to each other. The estimated coefficient for absolute Nifty returns $(0.033100)$ is positive but there is no statistically significant association. It indicates that there is no association between the market size and future market volatility. The literature documented that the market size movement and the future market volatility holds contemporaneous relation.

The estimated coefficients for one lagged period nifty returns are positively significant with IVIX which implies that the past Nifty returns have a significant influence on the future market volatility. These results are confirming the earlier results.

The combined positive coefficient $\Gamma(-0.123264)$ and combined negative coefficient $\Gamma(0.057065)$ are estimated to understand the impact of positive and negative returns on IVIX. The study results have no significant evidence to support earlier studies.

\section{Summary and Conclusion}

The study employed a multiple regression model suggested by Fleming et al. (1995) to understand the intertemporal relationship between Nifty returns and IVIX; the study also presented the analysis during the COVID-I9 period.

The study result for the PRE-COVID-I9 sample suggests a considerable negative association between Nifty returns and IVIX. The results also recommend that there is no association between the size of the market and the expected market volatility. The lagged Nifty returns for two periods and one period lagged IVIX values are positively significant with IVIX change. The combined negative and positive Nifty returns effect on expected market volatility is not statically significant. This implies that the Nifty returns and IVIX value are independently moving with each other. The one period lagged Nifty returns and one period lagged IVIX values are significantly related to the nifty returns. It indicates that the past market returns and past volatility have a substantial influence on the expected future market volatility. The PRE-COVID-I9 period results are practically confirming the earlier studies results (Shaikh \& Padhi, 2015; Fleming et al., I995).

The COVID-I9 period results indicate very interesting facts about the Indian investors and their perceptions about the market volatility. The study findings reveal that the Market returns and its expected market volatility are moving independently. The market size and the market move also have no significant association; this implies that the Indian investors are not much worried about the fluctuation in the market returns or to its volatility during this pandemic period. The emerging-market investors might be taking the market decline as an opportunity to invest and market rise as an opportunity to sell the stocks. They are willing to trade based on the fundamentals than the market movements. This could be one of the reasons for the disappointment of IVIX futures in India. The study results are important for the fund managers, policymakers, and analysts to understand the dynamics of emerging market volatility and trading behavior of Indian investors. The country's geopolitical situations and liquidity situation of the market participants may also have a role in IVIX values. A detailed study to understand the influence of geopolitical situations on the IVIX values and market liquidity could help us to understand more details about the market participants and IVIX.

\section{References}

Bekaert, G., \& Wu, G. (2000). Asymmetric volatility and risk in equity markets. The review of financial studies, I3(I), I42.

Black, F. (1976). Studies of stock market volatility changes. 1976 Proceedings of the American Statistical Association Business and Economic Statistics Section. 
Campbell, J. Y., \& Hentschel, L. (I992). No news is good news: An asymmetric model of changing volatility in stock returns. Journal of Financial Economics 3I, 28I-3I8.

Chakrabarti, P., \& Kumar, K. K. (2020). High-Frequency Return-Implied Volatility Relationship: Empirical Evidence from Nifty and India VIX. The Journal of Developing Areas, 54(3).

Chandra, A., \& Thenmozhi, M. (2015). On asymmetric relationship of India volatility index (India VIX) with stock market return and risk management. Decision, 42(I), 33-55.

Chen, A. H., \& Siems, T. F. (2004). The effects of terrorism on global capital markets. European journal of political economy, 20(2), 349-366.

Chen, M. H., Jang, S. S., \& Kim, W. G. (2007). The impact of the SARS outbreak on Taiwanese hotel stock performance: an event-study approach. International Journal of Hospitality Management, 26(I), 200-2I2.

Dhanaiah, G., Reddy, D. R., \& Prasad, T. N. L. (20I2). India VIX: Examining the negative and asymmetric volatility index - market return relationship. Indian Journal of Finance, 6(5), 4-I0.

Fleming, J., Ostdiek, B., \& Whaley, R. E. (1995). Predicting stock market volatility: A new measure. Journal of Futures Markets, I5(3), 265-302.

Fousekis, P. (2020). Sign and size asymmetry in the stock returns-implied volatility relationship. The Journal of Economic Asymmetries, 21, e00162.

French, K. R., Schwert, G. W., \& Stambaugh, R. F. (1987). Expected stock returns and volatility. Journal of financial Economics, $I$ ( $(\mathrm{I}), 3$.

Frijns, B., Tallau, C., \& Tourani-Rad, A. (2010). Australian implied volatility index. JASSA, (I), 3I.

Hibbert, A. M., Daigler, R. T., \& Dupoyet, B. (2008). A behavioral explanation for the negative asymmetric returnvolatility relation. Journal of Banking \& Finance, 32(10), 2254-2266.

Kudryavtsev, A. (2017). VIX Index and Stock Returns Following Large Price Moves. Journal of Risk \& Control, 4(I), 7I-IOI.

Merton, R. C. (1973a). An intertemporal capital asset pricing model. Econometrica: Joumal of the Econometric Society, 867-887.

Merton, R. C. (1973b). Theory of rational option pricing. The Bell Journal of economics and management science, I4II83.

Papakyriakou, P., Sakkas, A., \& Taoushianis, Z. (2019). The impact of terrorist attacks in G7 countries on international stock markets and the role of investor sentiment. Journal of International Financial Markets, Institutions and Money, 61, I43-I60.

Shaikh, I., \& Padhi, P. (20I5). On the Relationship of Ex-ante and Ex-post Volatility: A Sub-period Analysis of S\&P CNX Nifty Index Options. Journal of Emerging Market Finance, I4(2), I40-I75.

Siddiqui, S., \& Roy, P. (2019). Asymmetric relationship between implied volatility, index returns and trading volume: an application of quantile regression model. Decision 46, 239-252 (2019). https://doi.org/I0.1007/s40622019-00218-5

Skiadopoulos, G. (2004). The Greek implied volatility index: construction and properties. Applied Financial Economics, I4(16), I I87-II96.

Whaley, R. E. (2009). Understanding the VIX. The Journal of Portfolio Management 35, 98-I05.

ihttps://www.outlookindia.com/outlookmoney/equity/covid-I9-impact-on-stock-market-4666

\section{Copyrights}

Copyright for this article is retained by the author(s), with first publication rights granted to the journal. This is an openaccess article distributed under the terms and conditions of the Creative Commons Attribution license (http://creativecommons.org/licenses/by/4.0/). 